\title{
Robot-assisted edge machining using special tooling
}

\section{Belomesnykh Aleksandr}

Candidate of Engineering Sciences, Associate Professor of the Department of «Technology and Equipment of MachineBuilding Production»

Federal State Budget Educational Institution of Higher

Education «Irkutsk National Research Technical

University»

Irkutsk, Russia

e-mail: Berkut1@mail.ru

Sidorova Alyona

Graduate student

Federal State Budget Educational Institution of Higher

Education «Irkutsk National Research Technical

University»

Irkutsk, Russia

e-mail: alenaivanova.91@ mail.ru

Abstract-The article analyzes the results of studies on robotassisted edge machining using specially designed tooling. Application of the specially designed tooling along with a synthesized system setting method ensured preset accuracy and surface quality, improved machining performance and operation stability

Keywords- Edge machining, robot-assisted machining, surface roughness, machining accuracy

\section{INTRODUCTION}

Edge machining is a crucial task in machine building. In particular, after cutting, most parts have burrs, which have to be removed. In Irkutsk Aviation Plant, edge machining is a manual operation. The method is labor consuming. It is characterized by poor quality and performance, high surface gouging risks and development of other machining errors. Studies on abrasive edge machining are promising [7]. However, tools applied for edge machining are not abrasion resistant [6].

The Department of Machine Building Technology and Production of Irkutsk National Research Technical University carried out some experiments on edge machining robotization [8]. As a part of contract works, a robotic system (RS) computerizing deburring, burring and edge rounding processes was designed. The RS consists of KUKA KR210 R2700 extra with an additional linear axis KUKA KL 1000-2, a high-speed spindle RC90/22, and a force sensing system (Fig.1).

\author{
Chapyshev Aleksandr \\ Candidate of Engineering Sciences, Associate Professor of \\ the Department of «Technology and Equipment of Machine- \\ Building Production» \\ Federal State Budget Educational Institution of Higher \\ Education «Irkutsk National Research Technical \\ University» \\ Irkutsk, Russia \\ e-mail: chapyshev_ap@irkut.ru
}

\section{Semyonov Evgeniy \\ Graduate student}

Federal State Budget Educational Institution of Higher Education «Irkutsk National Research Technical University» Irkutsk, Russia e-mail: sam.jlnex@mail.ru

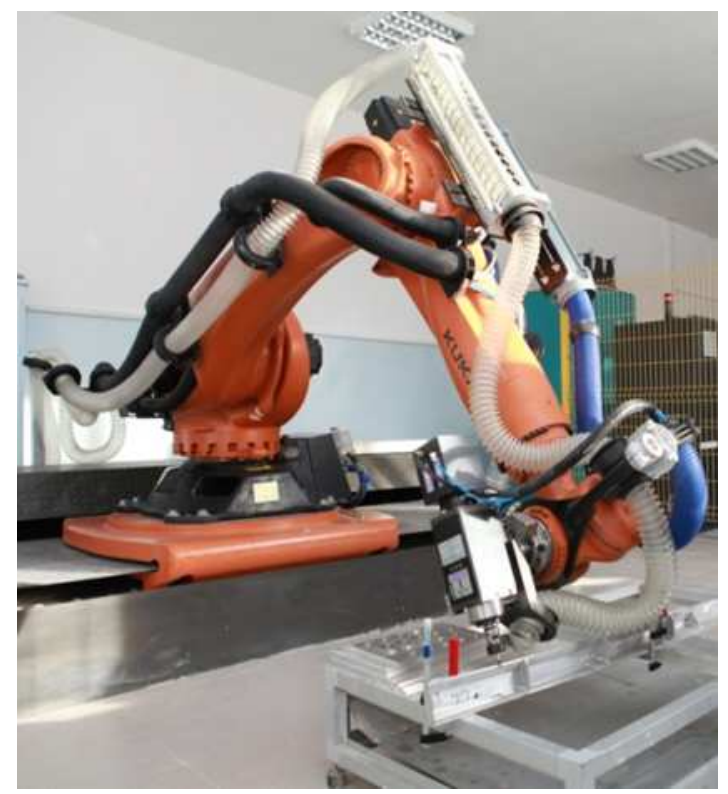

Fig. 1. Robot-assisted edge milling

According to the results of preliminary testings [1], [2] high-speed edge milling (at a speed rate of more than 5 $\mathrm{mm} / \mathrm{sec}$ ) reduces machining stability and accuracy. A free milling scheme is characterized by low cutting forces (they are close to the minimum response of the force sensing system), low rigidity, high probability of self-oscillations [3], [4] at increased values of $K R$ parameters $(K R>0.2)$. These factors have a negative impact on RS application potential for edge machining. New RS enhancement methods have to be developed. The article presents the results of application of milling tools developed by the robotics laboratory of INRTU. 


\section{MATERIALS AND METHODS}

Aluminum alloy V95pchT2 samples 150x50x2 mm in size were used in the experiments.

To improve machining accuracy, stability and performance, special tools with support rolling elements FIR.02 and FIR.03 were developed. Cutting parts are coned cutters $8 \times 13 \mathrm{~mm}$ and $13 \times 18 \mathrm{~mm}$ in size. The mill nose angle is 900. For tool setting a cylindrical moving element fixed in a required direction is used. The tool is installed in a standard tooling setup as can be seen in Fig. 2..

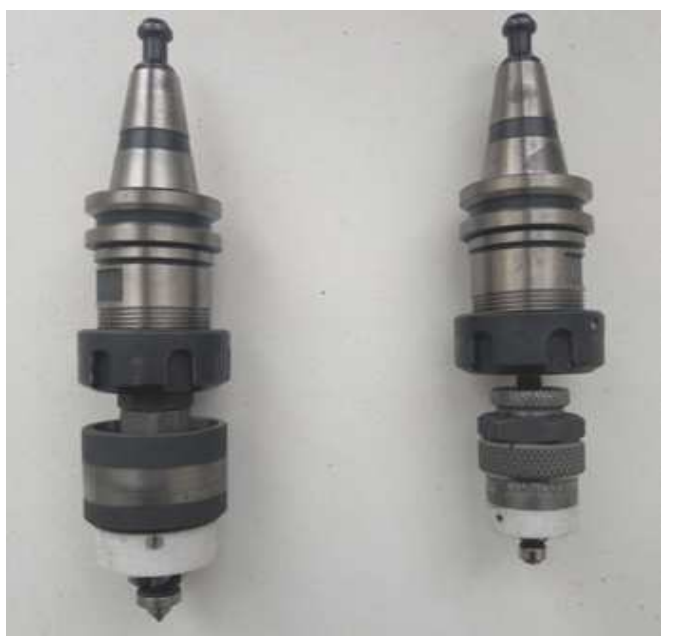

Fig. 2. Tooling setups with FIR.03 and FIR.02

Taking into account expected effects of the eccentric mass on the milling quality [5], the tooling setup with FIR.03 was prebalanced using HAIMER TD2009. Balancing class was 5.3. The threshold rotation frequency was 10000 min-1. FIR.02 was not balanced. Balancing class was 48.5.

The tooling setup was insterted in the spindle (see Fig. 3).

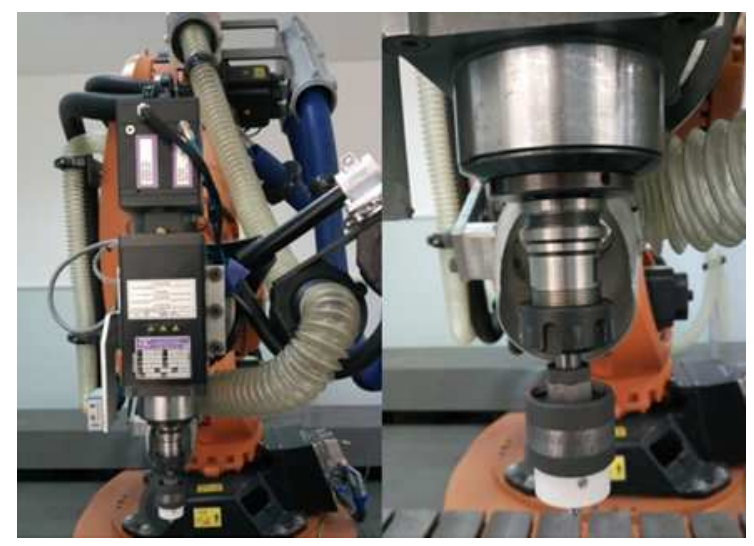

Fig. 3. Tooling setup inserted in RC $90 / 22$

Then the tooling was calibrated using methods involving contact and force closure, sizing, configuration memorization, and system activation. A distinctive feature of the synthesized method is single calibration and memorization followed by reproduction of the fixed tool extension value. It eliminates setting errors when calibrating the tool for machining a new part.
To determine the workpiece-tool press value, forces of open-circuit operation were assessed (the spindle was rotating). The experimental spindle force-torque diagram is presented in Fig. 4.

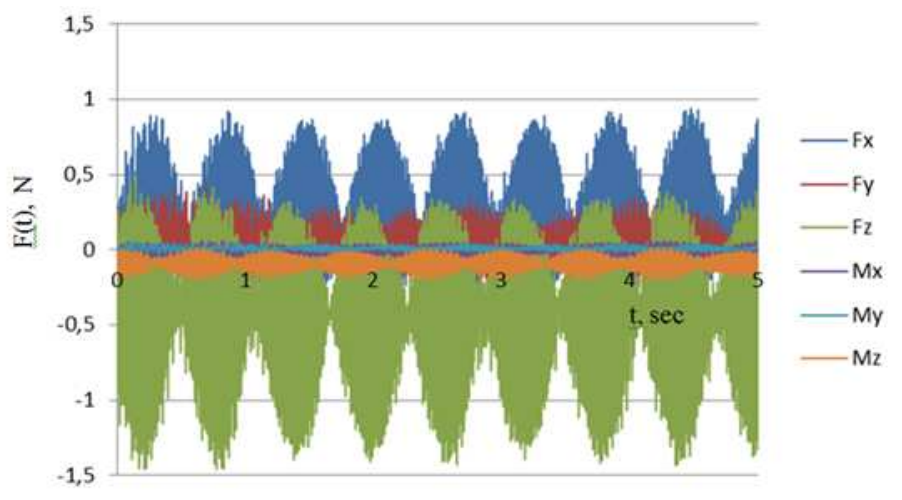

Fig. 4. Diagram of forces $F(t)$ and torques when the spindle rotates freely

With regard to recorded force amplitudes, the force setting value $\mathrm{P}=5 \mathrm{H}$ was set. It exceeds force $\mathrm{F}(\mathrm{t})$ in open circuit operations for ensuring reliability of workpiece-tool pressing. To increase force control system sensitivity, KR=0.6 was set.

Machining parameters were as follows: spindle rotation frequency was in the range from 2500 to $10000 \mathrm{rpm}$, feed was in the range from 5 to $20 \mathrm{~mm} / \mathrm{sec}$. Workpieces were machined along the $\mathrm{OX}$ and $\mathrm{OY}$ axes.

Surface roughness and edge chamfer sizes were analyzed. According to customer's technological requirements, the chamfer size has to be in the range from 0.1 to $0.4 \mathrm{~mm}$, roughness Ra has to be less than $3.2 \mathrm{um}$. Output parameters were measured using Taylor Hobson Form Talysurf. To study machining stability, the chamfer size was measured in eight segments spaced $20 \mathrm{~mm}$ apart. Ra was measured between these segments spaced.

\section{RESULTS AND DISCUSSION}

Fig. 5 shows the curves of the relationship between surface roughness, feed and a checkpoint number (positions of the segment along the edge) for spindle rotation frequency of 10000 min-1 for FIR.03.

According to the results, the surface quality at all parameters is satisfactory. The maximum microrelief instability is observed in initial edge segments. This effect increases with a rising feed rate.

To test machining capabilities of FIR.03, roughness was analyzed when the edge was located along the OY axis at a feed rate of $20 \mathrm{~mm} / \mathrm{sec}$. The results are presented in Fig. 6 . 


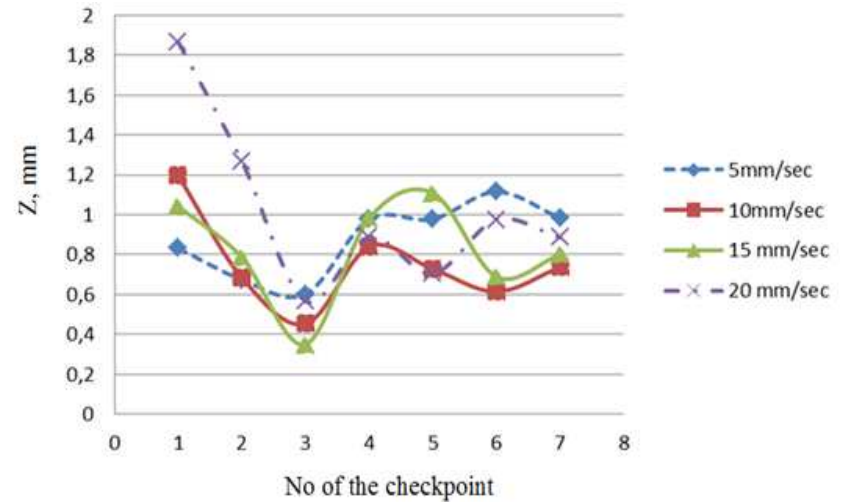

Fig. 5. Changes in surface roughness along the machined edge at different feed rates. The tool applied is FIR.03. The spindle rotation frequency is $10000 \mathrm{rpm}$. The edge is along the OX axis.

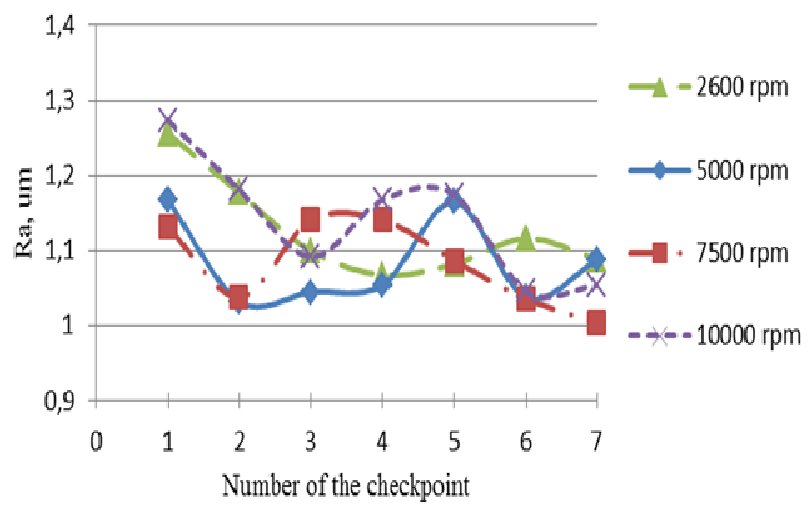

Fig. 6. Changes in surface roughness along the machined edge surface. The tool applied is FIR.03. The feed rate is $20 \mathrm{~mm} / \mathrm{sec}$. The edge is along the OY axis

The results show satisfactory machining quality along the workpiece edge. Moreover, when edge machining, microprofile stability is higher along the OY axis than along the OX axis. Thus, the part has to be installed so that vital surfaces are along the OY axis.

Fig. 7 shows the experimental relationship between the chamfer size, spindle rotation frequency and a checkpoint number along the $\mathrm{OY}$ axis at a feed rate of $20 \mathrm{~mm} / \mathrm{sec}$.

According to the data obtained, the chamfer size increases up to $0.35 \ldots 0.38 \mathrm{~mm}$ at the start of the toolpath. Then the chamfer size decreases up to $0.1 \ldots 0.15 \mathrm{~mm}$. Thus, even at high-productivity parameters, machining accuracy is sufficient.

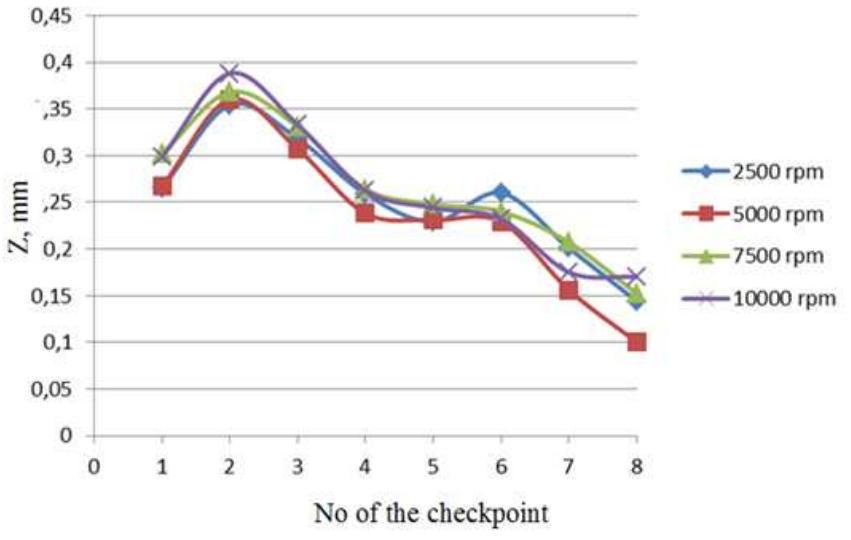

Fig. 7. Changes in chamfer dimensions along the machined edge. The tool applied is FIR.03. Spindle rotation frequencies are $2500 . .10000 \mathrm{rpm}$, the feed rate is $20 \mathrm{~mm} / \mathrm{sec}$. The edge is along the OY axis.

The analysis results for FIR.02's capabilities are presented in Fig. 8, 9 .

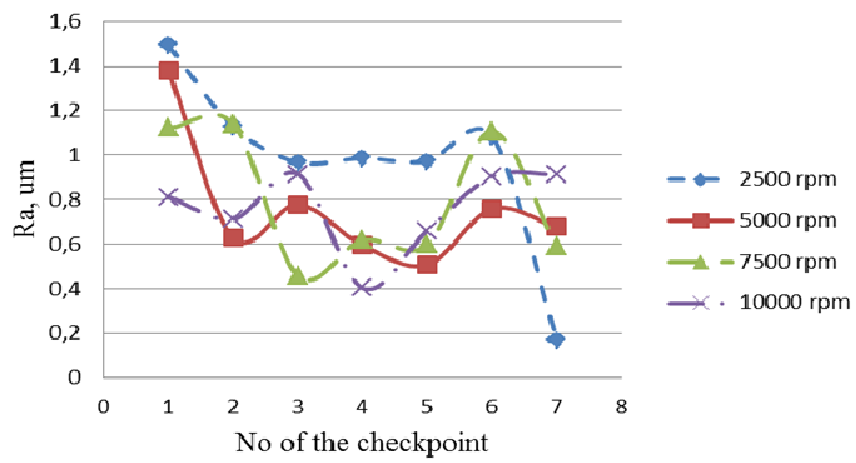

Fig. 8. Changes in surface roughness along the machined edge surface. The tool applied is FIR.02. Spindle rotation frequencies are $2500 \ldots 10000 \mathrm{rpm}$, the feed rate is $20 \mathrm{~mm} / \mathrm{sec}$. The edge is along the $\mathrm{OX}$ axis

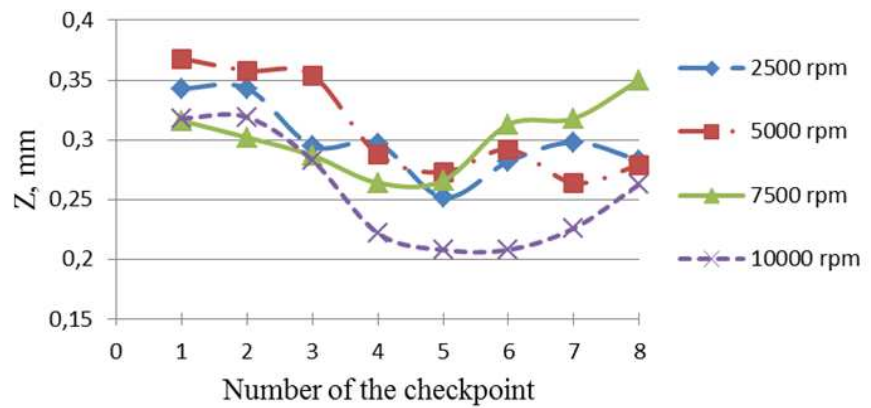

Fig. 9. Changes in the chamfer dimensions along the machined edge. The tool applied is FIR.02, the feed rate is $20 \mathrm{~mm} / \mathrm{sec}$. The edge is along the OY axis

For all parameters, accuracy and surface quality are satisfactory which speaks for high efficiency of the designed tooling and synthesized tool presetting methods. 


\section{CONCLUSION}

Application of the specially designed tools with cradles and a synthesized system setting method improved operation performance in comparison with manual operations from 0,05 up to $20 \mathrm{~mm} / \mathrm{sec}$ at a pre-set accuracy level of $0,25 \pm 0,15 \mathrm{~mm}$ and surface quality of $\mathrm{Ra}<3,2 \mathrm{um}$.

Machining stability was assessed by variations of $\mathrm{Ra}$ and chamfer dimensions along the $\mathrm{OX}$ axis higher than along the $\mathrm{OY}$ axis of the robot coordinate system.

Balanced FIR.03 showed better machining quality and accuracy results. Unbalanced FIR.02 ensured acceptable milling quality. Therefore, preliminary balancing is not obligatory for special tooling used for robot-assisted machining.

\section{References}

[1] A. Ivanova, A. Belomestnyh, E. Semenov, B. Ponomarev "Manufacturing capability of the robotic complex machining edge details", International Journal of Engineering and Technology (IJET), Vol 7, No 5 Oct-Nov 2015, pp.1774-1780.
[2] E.N. Semyonov, A.V. Sidorova, A.E. Pashkov, A.S. Belomestnykh "Accuracy assessment of KUKA KR210 R2700 extra industrial robot", International Journal of Engineering and Technology, 2016, V. 16. No 1, pp. 19-25.

[3] D.P. Aleynikov, A.V. Lukyanov "Simulation of the cutting forces and determination of vibrodiagnostics symptoms of end mill defects", Sistemy. Metody. Tekhnologii [Systems. Methods. Tehnologies], 2017, No. 1 (33), pp. 39-47.

[4] D.A. Lukyanov, D.P. Aleynikov, A.V. Luk'yanov "Calculation of parameters and visualization of spatial vibrations of machining center spindle by vibration measurement results", Vestnik of ISTU, Irkutsk, 2013, Vol. 12(83), pp. 92-99.

[5] Andrei Savilov, Dimitry Nikolaev, Andrei Nikolaev "Study of instrumental adjustment imbalance effect on milling output parameters", Vestnik of ISTU, Irkutsk, 2015, Vol. 7(102), pp. 81-91.

[6] V. Koltsov, D. Starodubtseva "Investigation of Interaction Traces between Flap Wheel and Aluminum Alloy Plain Surface", Procedia Engineering, 2017, pp. 473-478

[7] Y.V. Dimov, D.B. Podashev "Efficient machining by elastic abrasive wheels", Russian Engineering Research, 2017,V. 37. No 7, pp. 655-659.

[8] A.V. Savilov, A.C. Pyatykh, S.A. Timofeev "Modern optimization methods of milling operations", Proceedings of Samara scientific center, Russian Academy of Sciences, Samara, V. 15, No 6 (2), 2013, pp. 476479 . 